\title{
O luto em instituições de abrigamento de crianças ${ }^{1}$
}

\section{Coping with bereavement in children's sheltering}

\author{
Valéria TINOCO \\ Maria Helena Pereira FRANCO2
}

\begin{abstract}
Resumo
Este estudo teve como objetivo conhecer e refletir sobre o luto e os fatores de risco e proteção presentes no processo de institucionalização da criança em casas abrigo, a partir da prática de seus cuidadores. Foram analisados recortes de supervisões de cinco cuidadoras de nível técnico que trabalhavam em instituições de abrigo de crianças e que eram participantes de um grupo de supervisão coordenado pela autora. Estudar a respeito da prática dos cuidadores no processo de institucionalização foi importante para visualizar como a instituição pode interferir positiva e negativamente no processo de recuperação emocional após a separação da família, minimizando, ou não, problemas futuros de vinculação. A instituição e todos os envolvidos neste processo têm a possibilidade de prover grande parte dos fatores de proteção relacionados ao período de institucionalização, abrindo-se um caminho para pensarmos em intervenções preventivas e terapêuticas para a criança abrigada.
\end{abstract}

Unitermos: Criança. Cuidado substituto. Fator de risco. Luto. Vínculo.

\begin{abstract}
The aim of this qualitative study is to investigate and to reflect on bereavement, riskfactors and protection of children that exist in the process of child institutionalization, based on the practices of the carers. The analyzed sample was composed of sections of supervisions of five professional carers who worked for children's shelters. The study of the practices of the carers in the children's sheltering process was very important in order to perceive how the institution might have positive or negative impacts of family separation on the process of emotional recovery, by minimizing, or otherwise, future bonding problems. The institution, and everybody involved in this process, has the opportunity to provide protection factors related to the period of stay in the shelter, opening the way to thinking about prevention and therapeutic interventions for the sheltered child.
\end{abstract}

Uniterms: Child. Substitute caregiving. Risk. Bereavement. Bonds.

Estudiosos das décadas de 1940 e 1950, influenciados pelo número de crianças órfãs e pela inserção da mulher no mercado de trabalho após as duas guerras mundiais, apontaram a necessidade de se pesquisarem os efeitos da separação materna durante a infância.
Segundo Bowlby (1960/1999; 1990), vários de seus colegas psicanalistas e pesquisadores do comportamento e relacionamento humano dessa época reconheciam a importância vital de relação estável e permanente com uma figura materna amorosa, durante toda a infância.

$\operatorname{coth}$

' Artigo elaborado a partir da dissertação deV.TINOCO, intitulada "O luto em instituições de abrigamento: um desafio para cuidadores temporários". Pontifícia Universidade Católica de São Paulo, 2007.

2 Pontifícia Universidade Católica de São Paulo, Programa de Pós-Graduação em Psicologia Clínica. R. Monte Alegre, 984, Perdizes, 01723-020, São Paulo, SP, Brasil. Correspondência para/Correspondence to: V.TINOCO. E-mail: <valeria.tinoco@4estacoes.com>. 
Outros estudos (Aubry, 2004; Bowlby, 1993a, 1993b; Bromberg, 1998; Franco \& Mazorra Hughes, 2007; James, 1994; Jewett, 1994; Sanches, 2005) relacionam a existência de distúrbios psicológicos e problemas psiquiátricos na infância e na fase adulta com a experiência de separação, abandono, perda dos pais e/ou outros tipos de perda na infância.

Não só a perda é tida como a causadora de distúrbios, mas, principalmente, as consequências e acontecimentos que a precedem e a sucedem (Bowlby, 1995, 1993b; Ferreira, 1984; Parkes, 2005; Rutter, 1979, 1985). Tão mais desestruturador será para a criança se, além da separação e perda, ela não tiver alguém para assumir seu cuidado, não puder expressar seus sentimentos e tê-los compreendidos, tiver vivido perdas anteriores mal elaboradas e passar por novas perdas.

Crianças têm a experiência de estar separadas temporária ou definitivamente de seus pais, por motivos diversos: morte do(s) genitor(es), abandono, rejeição, incapacidade de cuidado por parte do(s) genitor(es) (abuso, negligência, abuso de álcool ou drogas, prisão, doença mental, doença física, falta de condição financeira, dificuldades geradas pela pobreza) e causas desconhecidas. Quando ocorre alguma ou algumas dessas situações e não há outra pessoa da família imediatamente capaz de assumir o cuidado da criança, sob consentimento do Estado, uma instituição de abrigamento se responsabiliza provisoriamente pelo seu cuidado, até que seja encontrada uma alternativa.

Dessa forma, em uma instituição que acolhe crianças cujos pais não podem zelar pelo seu cuidado, histórias envolvendo algum tipo de perda e sofrimento estão sempre presentes: as crianças chegam ao abrigo após ter passado por alguma situação de separação (provisória ou definitiva), abandono e/ou morte. Nessa população, tais experiências muitas vezes são somadas a outras de trauma e dor, como abuso, violência e negligência, que por sua vez geram outros tipos de perdas, como perda da segurança, da inocência e da confiança no outro e no mundo.

A passagem pela institucionalização é intensa e difícil para todos os envolvidos: criança, pais, familiares, profissionais. Trata-se de uma experiência que exigirá um processo de readaptação e recuperação, envolvendo a vivência de um processo de luto pelas mudanças, separações e perdas vividas. Entendendo o luto como uma reação ao rompimento de um vínculo (Bowlby, 1993b; Bromberg, 1998; Franco, 2002; Parkes, 1998; Worden, 1998), na institucionalização de uma criança muitos lutos estão presentes.

Ao descrever a relação da criança com a mãe em sua presença e em sua ausência - e a influência dessa relação na compreensão da personalidade, a Teoria do Apego, formulada por John Bowlby, alcançou lugar de destaque na compreensão da formação e do rompimento dos vínculos afetivos. Conforme o autor, a qualidade do relacionamento da criança com seus cuidadores, assim como as experiências de separação e perda dessas relações, teriam interferência nos seus relacionamentos futuros (Bowlby, 1969/1993; 1993a; 1993b). Segundo seus estudos de 1969, a criança desenvolve o comportamento de apego à figura com quem mantém proximidade, comumente a mãe, buscando fonte de confiança e proteção. O desenvolvimento desse comportamento, essencial para a saúde mental, dá-se numa experiência de cuidado afetivo contínuo e duradouro com a mãe ou substituto, na qual tanto a criança quanto a figura materna sentem satisfação e prazer, originando assim uma relação de apego segura.

O que Bowlby quer dizer por cuidado contínuo, um dos vários termos questionados na época em que escreveu a teoria, é explicado por seu filho, R. Bowlby (2004). Segundo ele, são experiências de cuidado contínuo as relações que duram muitos anos e cujos períodos de separação sejam curtos a ponto de não causar grandes problemas nem traumas. Porém, não há como saber, de forma generalista, o tempo exato que pode levar uma separação para que não cause danos.

Schofield e Beek (2005) destacam que, para um desenvolvimento emocional saudável, a criança precisa acreditar que o cuidador está disponível. Ele deve ser acessível, atento, capaz de identificar as necessidades da criança, permitir a dependência e estar apto a prover as necessidades de proteção e cuidado, sem ser intrusivo. Assim, é formada uma base segura, como denomina Bowlby (1969/1993), e a criança sente-se livre para explorar, aprender, desenvolver-se e manejar a ansiedade, contando que pode voltar para o cuidador diante de algum perigo ou ameaça.

Apesar de o comportamento de apego estar ligado à satisfação das necessidades tanto de cuidados 
físicos quanto de amparo, a presença de afeto e proteção é mais importante do que a alimentação e outros cuidados. Isto é, para a formação e a manutenção do comportamento de apego, mais importante do que o cuidado físico são a demonstração explícita de afeto do cuidador e sua iniciativa e capacidade de acolher rapidamente o bebê (Bowlby, 1969/1993).

Em experiências de separação prolongada ou permanente, a criança é capaz de vincular-se a outras figuras e, quando também as perde, apresenta reações intensas. Porém, quando o processo de apegar-se e perder acontece muitas vezes, a criança vai se ligando cada vez menos, podendo não se apegar a mais ninguém, não reagindo às separações e reencontros (Bowlby, 1993a). Nessa situação, a ausência de reações pode levar a crer que a criança está aparentemente adaptada ao meio, mas essa é uma adaptação superficial, na tentativa de proteger-se de novas perdas. Se a criança possuir um cuidador substituto com quem possa se relacionar e que seja fonte de afeto, é possível que ela forme novas relações seguras após a vivência da separação ou perda. Caso contrário, se houver falta de afeto e cuidado e se as relações forem breves, as relações formadas poderão ser sempre passageiras e superficiais (Bowlby, 1993b).

Entendendo que o objetivo do comportamento de apego é manter o laço afetivo com a figura de apego, qualquer ameaça ou risco de perda desse laço gerará uma ação que vise a sua preservação. Quanto maior o risco de perda, mais intensas serão as reações para evitá-la. Nessa situação, todas as formas de comportamento de apego são ativadas: agarrar, chorar, experimentar raiva ou intensa aflição, protestar. Se o laço é restabelecido, a aflição é aliviada e os comportamentos de apego cessam; caso contrário, o esforço para recuperar a relação nunca cessa totalmente (Bowlby, 1993b). Isso quer dizer que o anseio de reaver a pessoa perdida pode diminuir de intensidade, mas permanecerá esse desejo, mesmo que inconsciente.

Por que falar de luto na instituição? As autoras deste estudo entendem que a separação vivida por uma criança que é abrigada, independentemente do motivo que a levou a isso, é uma situação que envolve a perda de um ou vários vínculos com pessoas e com seu meio. Essas perdas alteram o conhecimento que ela tinha do mundo até então, e exigem que ela passe por um processo de adaptação, buscando novos significados.
Mesmo aquelas que são separadas apenas temporariamente de sua família, ou aquelas que mantêm um contato constante com esta por meio de visitas, também vivenciam uma perda e devem se adaptar a ela. As crianças que chegam ao abrigo, tendo passado por uma série de rompimentos anteriores, têm de se adaptar à nova separação, às novas pessoas e ao novo lugar, podendo isso ser mais ou menos difícil, a depender de uma série de fatores relacionados às perdas vividas anteriormente e à experiência atual.

Devido à perda daquilo que era conhecido e à necessidade de se ajustar a uma nova situação, a criança passará por uma reestruturação emocional, que se dará por meio de um processo o processo de luto. Desse processo, quando vivido adequadamente, fará parte a compreensão do que aconteceu, as expressões de luto, a reorganização e construção de novos significados, a formação de novos vínculos ou recuperação dos vínculos dos quais esteve temporariamente separada, e a continuidade da vida de modo satisfatório, saudável e prazeroso.

A vivência da criança que é institucionalizada em uma casa abrigo normalmente envolve, além do afastamento de sua família e de sua casa, o afastamento de tudo o que lhe era conhecido: brinquedos, comidas, aromas, hábitos, contato com vizinhos e comunidade, escola, colegas, lugares conhecidos que frequentava. Trata-se, portanto, de uma experiência de múltiplos rompimentos, que requer a elaboração de múltiplos lutos.

Essa somatória de perdas é grande fonte de angústia para a criança e faz com que intensos comportamentos de procura sejam ativados. Em situações como esta, nem a figura humana, nem o meio físico, com os quais a criança mantinha uma relação de apego, estão disponíveis para protegê-la e aliviá-la de aflição.

Independentemente de a perda ser definitiva ou temporária e do quê/quem e como foi perdido, há que elaborá-la para tornar possível a adaptação à nova realidade e a formação de novos vínculos. No entanto, num primeiro momento pode ser difícil aceitar o que aconteceu, pois parece que com a aceitação o retorno à família fica mais distante. Ainda que a criança volte a conviver com sua família de origem, entende-se neste estudo que será um novo vínculo a ser formado, já que a relação que existia foi modificada pelos aconteci- 
mentos vividos, sendo necessário, portanto, um processo de elaboração dessa experiência.

É comum observarem-se reações nas crianças institucionalizadas, tais como: choro, tristeza, depressão, raiva, culpa, angústia, relutância em aceitar coisas novas, comportamentos agressivos, apatia, comportamentos regressivos como voltar a se comportar como uma criança mais nova, isolamento, queda no rendimento escolar, ansiedade, dificuldade de concentração, somatizações, problemas de sono e de alimentação. Este estudo entende tais manifestações como expressão de luto, que fazem parte de uma reação normal diante das perdas sofridas e que precisam ser acolhidas e entendidas como tal. Por outro lado, também é possível encontrar crianças que aparentemente não reagem às mudanças ocorridas. Isso se refere, segundo Hughes (2004), à dificuldade de ligar-se às pessoas e à falta de confiança para expressar seus sentimentos.

No processo de abrigamento, que normalmente envolve a vivência de experiências negativas, é comum a criança ter pouca ou nenhuma sensação de controle em relação ao que acontece com sua vida e em todo o entorno, além de uma intensa falta de confiança no adulto, já que sente que este a deixou. Por mais que a separação tenha ocorrido por outras questões que não o abandono, é comum a criança sentir-se abandonada, como também acontece quando ela perde um ente querido por morte. Tais afirmações são de acordo com Hunter (2001), quando diz que crianças que passaram pela ruptura de deixar a família de origem, normalmente, têm abalado seu senso de pertencimento e sua autoestima, percebendo aquele evento como rejeição, o que gera grande sentimento de insegurança.

Por desejar sentir-se segura em função do que foi vivido, a criança busca ter o controle de tudo o tempo todo, usa mecanismos de manipulação, procura satisfação imediata e apresenta tolerância mínima à frustração. Diante da impossibilidade de alcançar todos esses objetivos, situações de abandono e/ou violência acabam sendo recriadas pela criança, confirmando que essa é a única possibilidade de relacionamento que ela tem: não ter nenhuma (Hughes, 2004; Schneider \& Phares, 2005; Schofield \& Beek, 2005).

A partir dessa compreensão, pode-se situar a origem de tantas dificuldades de relacionamento entre 430 crianças e cuidadores, e entre crianças e seus pares, dentro da instituição: crianças fogem dos abrigos, brigam com os cuidadores e as outras crianças, não aceitam intervenção e recusam tentativas de aproximação, cuidado e afeto.

Segundo Hughes (2004), os cuidadores podem sentir que um problema de comportamento da criança representa uma dificuldade em sua capacidade de cuidar, e que portanto não estariam cumprindo bem seu papel. Nessa situação, sentimentos de raiva e impotência podem dominá-los e interferir em sua atitude frente à criança. Algumas reações do cuidador substituto apenas incrementam a desconfiança e a dificuldade em manter um vínculo saudável com a criança, como: quando esta se comporta de maneira evitativa, responder como se ela não necessitasse dele; quando se comporta de maneira resistente, responder de forma raivosa (Dozier, 2005).

Bowlby (1993b) destaca que o sucesso de uma nova relação não está vinculado ao esquecimento da relação anterior e, ao contrário disso, se as duas relações puderem se manter distintas e presentes, maior a possibilidade de que a nova relação dê certo. Isso pode ser difícil de ser sustentado pela figura que ocupa o novo lugar na relação, como, por exemplo, a mãe substituta ou o cuidador de um abrigo. Se a criança sente que tem de fazer uma escolha que pode ameaçar sua relação anterior, é possível que resista a se adaptar às novas pessoas e novas circunstâncias de vida.

Por outro lado, para ajudar a criança a elaborar sua história de perda, é essencial o desenvolvimento de um bom vínculo com um adulto (psicoterapeuta, cuidador de abrigo, técnico, pais adotivos) e com o ambiente, e, quando isso é alcançado, um passo foi dado no sentido da elaboração do luto. Segundo James (1994), a criança só poderá explorar a situação traumática e elaborar o luto quando sentir que está em um ambiente seguro e que não precisa se preocupar com sua sobrevivência. Durante esse processo, terá de desapegar-se da figura perdida e ligar-se a figuras novas, mas só poderá realizar o primeiro após estar minimamente ligada a alguém e segura.

Assim, este estudo parte do pressuposto de que a elaboração da experiência de institucionalização pode ser influenciada por variáveis presentes antes, durante e depois do abrigamento. Tais variáveis são chamadas "fatores de risco" ou "fatores de proteção", e podem 
dificultar ou facilitar o enfrentamento e a adaptação da criança à instituição e à nova realidade. É importante ressaltar que a presença ou ausência de um fator de risco ou proteção não determina, por si só, as consequências da experiência, mas, sim, a relação entre a presença e ausência de vários desses fatores.

Como apontado ao longo da revisão teórica, os fatores de risco e proteção podem estar relacionados à criança institucionalizada, a seu histórico de vida e rompimentos, à relação perdida, às circunstâncias de abrigamento e suporte recebido, principalmente no que se refere à disponibilidade da instituição em lidar com suas necessidades de apego.

Neste artigo apresentam-se reflexões a respeito do cuidado necessário à criança abrigada numa instituição, bem como acerca das perdas, lutos e fatores de risco e proteção envolvidos nesse processo, a partir da prática de seus cuidadores.

\section{Método}

Neste estudo qualitativo foram analisados recortes de supervisões de cinco cuidadoras de nível técnico (assistente social, pedagoga e psicopedagoga), que trabalhavam em instituições de abrigo de crianças e participavam de um grupo de supervisão coordenado pela primeira autora, entre 2003 e 2005. O grupo tinha por objetivo refletir sobre a prática das cuidadoras, fortalecendo ações que pudessem ajudar a criança em sua experiência de abrigamento (fatores de proteção), bem como diminuir os fatores prejudiciais a ela (fatores de risco). As cuidadoras tinham entre 28 e 50 anos de idade e tempo de trabalho em instituições de abrigamento de crianças variando entre 3 e 27 anos. 0 perfil das instituições de abrigamento à qual elas pertenciam era diverso, havendo instituição tanto de médio porte quanto do modelo "lar social". As instituições tinham sob sua responsabilidade crianças encaminhadas pela Vara da Infância e da Juventude, com ordem judicial de abrigamento por tempo indeterminado, e idade de zero ano a 17 anos e 11 meses.

Após se organizarem os registros do material de supervisão de cada participante, foi feita uma seleção dos temas emergentes de cada relato, a fim de se destacarem as informações que pudessem levar à compreen- são de como as cuidadoras percebem e atuam na experiência de institucionalização.

Os cuidados éticos adotados neste trabalho foram respaldados em documentos sobre pesquisas científicas com seres humanos no Brasil e sobre pesquisas na área de luto (Brasil, 1996; Cook, 2001; Conselho Federal de Psicologia, 2005; Parkes, 1995).

O trabalho no qual o presente artigo foi baseado recebeu parecer favorável junto ao Comitê de Ética em Pesquisa da Pontifícia Universidade Católica de São Paulo (protocolo n. 004/2007).

\section{Resultados e Discussão}

Os dados extraídos dos registros das supervisões relacionados a possíveis fatores de risco e/ou proteção foram selecionados e agrupados para serem analisados. O processo de seleção e agrupamento levou às seguintes categorias de análise: a) o vínculo entre o cuidador e as crianças abrigadas; b) a instituição diante da história da criança; c) as visitas das famílias biológicas às crianças; d) o desabrigamento por retorno à família de origem; e) o desabrigamento pela saída aos dezoito anos; f) o desabrigamento por adoção; g) a transferência para outra instituição; h) como lidar com situações de luto por morte ou doença na instituição; i) outros rompimentos dentro da instituição; j) preparo da equipe do abrigo para o cuidado das crianças. As categorias foram assim destacadas com o intuito de organizar os dados para posterior análise.

A análise das categorias foi realizada levando-se em conta a perspectiva dos fatores de risco e fatores de proteção, descritos a partir da revisão da literatura e da prática clínica e institucional das autoras. A partir dessa análise, puderam-se compreender algumas questões observadas na rotina dos abrigos, bem como as dificuldades e conquistas presentes no trabalho das cuidadoras.

As mudanças e rompimentos vividos na instituição de abrigo (saída de cuidadores, desabrigamentos, outras perdas) afetam todos os envolvidos no processo, embora nem sempre isso seja reconhecido, o que interfere no modo como são conduzidos. A prática nas instituições nas quais trabalhavam as cuidadoras participantes deste estudo é influenciada pela ideia de que a 
aproximação do sofrimento relacionado aos rompimentos pode trazer mais dor, e não a possibilidade de enfrentamento.

A dificuldade de reconhecimento parece estar associada à falta de preparo e apoio para lidar com o tema, tanto do ponto de vista pessoal quanto profissional. Percebe-se que situações de difícil solução, assim como a identificação com a dor das crianças, também aparecem como fatores que interferem no não reconhecimento das reações, podendo gerar certa paralisia nas cuidadoras.

No entanto, quando as cuidadoras se sentem apoiadas e respaldadas por recursos teóricos e técnicos adequados, são capazes de manejar tais situações, atuando de forma mais consciente diante das questões que envolvem rompimentos. O reconhecimento das reações de luto das crianças abrigadas faz com que tenham atitudes que facilitam a adaptação da criança à situação enfrentada, o que se considera aqui um fator de proteção.

Quando as transições são planejadas e executadas junto aos abrigados, parece que estes se sentem mais seguros e capazes de adaptar-se a elas. A instituição, por sua vez, consegue trabalhar mais efetivamente seus propósitos e minimizar os problemas de comportamento dos abrigados, saindo de uma sensação de paralisia e se identificando com a possibilidade de atuar eficientemente dentro desse contexto.

Observou-se também que, quando as cuidadoras atuam de modo a proporcionar fatores de proteção nos momentos de separação, tais experiências podem ser elaboradas e consequentemente integradas mais facilmente por todos, isto é, tanto por aqueles que estão institucionalizados quanto pelos cuidadores, e também por aqueles que passaram pela experiência de abrigamento e hoje estão fora da instituição. A possibilidade de manter a instituição em sua história, de ela ser uma base segura, assim como os vínculos formados dentro dela, parece ser um dos pontos-chave que funcionam como fator de proteção para essa população.

Por meio da análise das categorias apresentadas, foram identificados os seguintes fatores de risco e de proteção, presentes na prática das cuidadoras participantes da pesquisa:

- Fatores de risco: (a) não reconhecimento das

432 reações das crianças diante dos rompimentos; (b) falta de suporte adequado diante do não reconhecimento das manifestações aos rompimentos; (c) falta de preparo para mudanças e separações, como: desabrigamento, adoção, transferência para outra instituição, retorno à família, saída da instituição aos dezoito anos, saída dos cuidadores e crianças institucionalizadas; (d) dificuldade do cuidador em lidar com as emoções das crianças; (e) não reconhecimento pelos cuidadores dos próprios sentimentos em relação aos rompimentos que ocorrem na instituição e consequente falta de rede de apoio para eles; (f) violência dentro da instituição, por exemplo, abuso sexual; (g) não valorização das relações formadas dentro da instituição; (h) abrigamentos e desabrigamentos sucessivos; (i) carência de formação especializada para trabalhar com a população de abrigo.

- Fatores de proteção: (a) relação de apego segura com cuidadores da instituição, incluindo afeto, confiança e preservação da relação; (b) interesse e empatia de adultos cuidadores para com a criança; (c) inclusão da criança em assuntos que lhe dizem respeito, com clareza e verdade; (d) preparo dos cuidadores para lidar com as demandas específicas da criança abrigada; (e) ações coordenadas entre a rede de cuidado da criança, de dentro e fora do abrigo; (f) possibilidade de manter vínculos com os cuidadores, tanto após o desabrigamento quanto após terem estes se desligado da instituição; (g) preparação para a saída da instituição; (h) facilitação da elaboração do luto por morte: possibilidade de expressão dos sentimentos, reconhecimento das manifestações de luto, resposta a dúvidas, acompanhamento de um cuidador de confiança da criança; (i) facilitação e estímulo da relação entre as crianças; (j) existência de projetos e programas preventivos e preparatórios para o enfrentamento de diferentes situações no abrigo; (k) promoção de capacitação de cuidadores diretos para o cuidado especializado da criança abrigada.

Por meio da análise do material, foram identificados comportamentos e manifestações de luto da criança abrigada, bem como o modo como as cuidadoras compreendem e lidam com os mesmos. Quando as cuidadoras assumem uma postura em que é permitido falar de assuntos difíceis e dolorosos, reconhecendo e validando as reações e comportamentos, os adultos envolvidos no processo de abrigamento e desabrigamento da criança podem desempenhar ações profiláticas relacionadas à formação e rompimento de 
vínculos, evitando a somatória de novos riscos. Percebeu-se que, quando se sentem apoiadas, as cuidadoras são capazes de lidar com esses temas difíceis, sendo o espaço da supervisão adequado para isso.

\section{Considerações Finais}

Ao longo deste trabalho buscou-se trazer para a experiência da institucionalização das crianças em abrigos a importância de lidar com a formação e rompimento de vínculos a partir da Teoria do Apego.

Quando se escolheu este tema para ser estudado, tinha-se clareza de que o processo de adaptação aos rompimentos era apenas um dos inúmeros aspectos envolvidos na experiência de ida para um lar substituto. Ao destacar esse aspecto, esta pesquisa pretendeu incrementar os estudos existentes, bem como aumentar a possibilidade de ajudar a significar o momento de perda vivido pelas crianças, além de facilitar o relacionamento entre os vários personagens envolvidos - crianças, profissionais, família de origem e família adotiva. Este estudo focalizou especialmente os fatores de risco e proteção para a elaboração dos rompimentos presentes no processo de institucionalização, por se entender que eles são essenciais à elaboração da institucionalização propriamente dita. O estudo permite concluir que o processo de institucionalização envolve um enorme complexo de relações permeadas por rompimentos, e assim necessita de reflexões e ações em diferentes instâncias e para diferentes sujeitos. Se a formação de vínculos afetivos é entendida como fator crucial para uma vida com relações seguras, que per-mitam o crescimento e a saúde emocional do indivíduo, é imprescindível o trabalho com o rompimento e a formação de vínculos dessas crianças, já que tal situação faz parte do cotidiano da instituição.

Para que a instituição seja uma alternativa positiva diante de uma família que não tem condições de cuidar de sua criança, é preciso que seja um lugar que não incremente sua história de perdas e, além disso, que seja um bom lugar de se morar, que possa fazer parte de sua história, não constituindo apenas uma função de passagem, mas uma experiência de segurança e crescimento, independentemente do tempo de permanência nela.
O presente estudo mostrou-se limitado quanto à possibilidade de avaliar o impacto das experiências pessoais de perda e luto dos cuidadores na atuação junto à criança abrigada, o que pode ser considerado para pesquisas futuras. A atuação de cuidadores não técnicos, que não esteve incluída neste estudo, também merece destaque em novos estudos.

A partir dessas reflexões, tornam-se necessárias muitas outras, com o intuito de desenvolver práticas e políticas de prevenção e intervenções adequadas, na tentativa de aumentar os fatores de proteção e reduzir os fatores de risco para a saúde mental da criança em situação de abrigamento. Pesquisas que visem formar profissionais de saúde aptos a trabalhar com perdas, neste e em outros contextos, devem continuar sendo exploradas.

\section{Referências}

Aubry, J. (2004). Psicanálise de crianças separadas: estudos clínicos. Rio de Janeiro: Companhia de Freud.

Bowlby, J. (1990). Formação e rompimento de laços afetivos. São Paulo: Martins Fontes.

Bowlby, J. (1993). Apego (Vol.1). São Paulo: Martins Fontes. (Originalmente publicado em 1969).

Bowlby, J. (1993a). Separação: angústia e raiva (Vol.2). São Paulo: Martins Fontes.

Bowlby, J. (1993b). Perda: tristeza e depressão (Vol.3). São Paulo: Martins Fontes.

Bowlby, J. (1995). Cuidados maternos e saúde mental. São Paulo: Martins Fontes.

Bowlby, J. (1999). Aflição e luto na infância. In Littoral. Luto de criança. Rio de Janeiro: Companhia Freud. (Originalmente publicado em 1960).

Bowlby, R. (2004). Fiftyyears of attachment theory: the Donald Winnicott memorial lecture. London: Kar.

Bromberg, M. H. P. F. (1998). Psicoterapia em situações de perda e luto. Campinas: Livro Pleno.

Cook, A. S. (2001). The dynamics of ethical decision making in bereavement research. In M. S. Stroebe, R. O. Hansson, W. E. Stoebe \& H. Schut. Handbook of bereavement research: consequences, coping and care (pp.119-142). Washington: American Psychological Association.

Dozier, M. (2005). Challenges of foster care. Attachment and Human Development, 7, 27-30.

Ferreira, M. C. R. (1984). O apego e as reações da criança à separação da mãe: uma revisão bibliográfica. Cadernos de Pesquisa, 48, 3-19. 
Franco, M. H. P. (2002). Uma mudança no paradigma sobre o enfoque da morte e do luto na contemporaneidade. In M. H. P. Franco (Org.), Estudos avançados sobre o luto (pp.15-38). Campinas: Livro Pleno.

Franco, M. H. P., \& Mazorra, L. (2007). Criança e luto: vivências fantasmáticas diante da morte do genitor. Estudos de Psicologia (Campinas), 24 (4), 503-511. doi: 1590/S0103-1 66X2007000400009.

Hughes, D. A. (2004). Building the bonds of attachment: awakening love in deeply troubled children. Lanham: Rowman \& Littlefield.

Hunter, M. (2001). Psychotherapy with young people in care: lost and found. Philadelphia: Brunner-Routledge.

James, B. (1994). Handbook for treatment of attachmenttrauma: problems in children. New York: Free Press.

Jewett, C. (1994). Helping children cope with separation and loss. London: Barsford.

Parkes, C. M. (1995). Guidelines for conducting ethical bereavement research. Death Studies, 19, 171-181.

Parkes, C. M. (1998). Luto: estudos sobre o pesar na vida adulta. São Paulo: Summus.

Parkes, C. M. (2001). A historical overview of the scientific study of bereavement. In M. S. Stroebe, R. O. Hansson, W. E. Stoebe \& H. Schut. Handbook of bereavement research: consequences, coping and care (pp.25-45). Washington: American Psychological Association.

Rutter, M. (1979). Maternal deprivation 1972-1978: new findings, new concepts, new approaches. Child Development, 50, 283-305.

Rutter, M. (1985). Resilience in face of adversity: protective factors and resistence to psychiatric disorder. British Journal of Psychiatry, 147, 598-611.

Rutter, M. (1993). Resilience: some conceptual considerations. Journal of Adolescent Health, 14, 626-631.

Sanches, R. M. (Org.). (2005). Winnicottna clínica ena instituição. São Paulo: Escuta.

Schneider, K. M., \& Phares, V. (2005). Coping with parental loss because termination of parental rights. Child Welfare, $84,819-842$

Schofield, G., \& Beek, M. (2005). Providing a secure base: parenting children in long-term foster care. Attachment and Human Development, 7, 3-27.

Worden, J. W. (1998). Terapia do luto: um manual para o profissional de saúde mental. Porto Alegre: Artes Médicas.

Recebido em: 3/4/2009

Versão final reapresentada em: 24/11/2010

Aprovado em: 12/4/2011 